\title{
Automatic device for remote measuring of circularity: Development and implementation in education courses
}

\author{
Slobodan Dudić, Jovan Šulc*, Vule Reljić, Brajan Bajči, Dragan Šešlija and Ivana Milenković \\ Department of Industrial Engineering and Engineering Management, Faculty of Technical Sciences, University of Novi Sad, Novi Sad, \\ 21000, Serbia \\ *Corresponding Author : sulc@uns.ac.rs
}

Submitted : 20/02/2020

Revised :25/02/2021

Accepted : 10/03/2021

\begin{abstract}
In conjunction with the development of technology, teaching in educational institutions around the world has also changed from traditional teaching, where blackboards and chalk were used, to modern teaching with blended or completely online learning environments. Online teaching became a necessity over the past year as the COVID-19 pandemic occurred throughout the world. One of the biggest problems that arose was the impossibility of students to work with equipment on the spot during laboratory exercises. In turn, many universities have used labs with physical devices that can be launched remotely through the Internet from anywhere. One such device is presented in this paper. An automatic device for the remote measurement of geometric tolerances, circularity, was developed and applied in the teaching process at the University of Novi Sad. The exercises were performed by students who remotely started and controlled the device and measured the deviation of the actual from the defined diameter of the work piece in the desired cross section. At the end of the semester, students completed an evaluation questionnaire and expressed satisfaction with the implementation of this exercise.
\end{abstract}

Keywords: Remote laboratory; Distance learning; Online education; Geometrical tolerances; Circularity; Remote measurement.

\section{INTRODUCTION}

During the previous year, the COVID-19 pandemic disrupted the world, which led to changes in the traditional way of life, business, and, of course, education. Previously known teaching processes, which included the use of blackboard and chalk, have now been partially or completely replaced by a new teaching process: online via the Internet. To maintain quality of higher education activities and ensure quality teaching continues in spite of the changed circumstances, universities have started to apply new methods in their learning processes. These methods use distance learning (Sit and Brudzinski, 2017, and Faulconer et al., 2018), as well as virtual (Alkhaldi et al., 2016, and Caminero et al., 2016) and remote laboratories. 
Remote laboratories represent systems with real, physical devices or experimental setups that allow performing tasks or measurements and can be accessed from remote locations. The use of remote laboratories helped partially solve one of the biggest problems that arose in teaching during the previous year (the impossibility of students to work with the equipment on the spot during laboratory exercises). This is very important, especially in the field of engineering studies as working in a laboratory environment is essential (Caminero et al., 2016). Namely, practical work and laboratory activities that includes hardware setups increase students' achievement and interest (Alkhaldi et al., 2016). Also, using remote laboratories allows the availability of a physical, experimental setup to many users, theoretically, 24 hours a day. This is one of the reasons why the number of remote laboratories increased in the last few years (Lowe et al., 2015). In addition to the students, users of this type of laboratory can be industrial professionals, teachers, etc. One of the main advantages of remote laboratories is that users can plan their activities according to their preferences.

Remote laboratories have been developed successfully in various fields of education. This includes the development of several remote laboratories to handle the topic of basic control of electric motors (Irmak et al., 2011, and Tekin et al., 2012). Remote laboratories for more complex systems, such as mechatronics systems are also very popular (Rojko et al., 2011, Kaluz et al., 2015., Luthon et al., 2015, Geaney and O’Mahony, 2016, Dos Santos Lopes et al., 2017, Reljic et al., 2018). From the field of signal processing, remote laboratories are developed for analogue and digital signal communication (Yayla et al., 2008, and Krneta et al., 2012). In addition, remote laboratories appear in science education, e.g., in physics (Axaopoulos et al., 2012, and Ozvoldova et al., 2014).

Remote laboratories can also be applied in the field of education in mechanical and industrial engineering. Namely, quality is one of the requirements for the competitiveness of each product on the market. In the case of the development of mechanical elements and parts, quality indicators are primarily dimensional, including the accuracy of the shape and positioning, as well as the quality of the treated surface.

The absolute accuracy of the given dimensions can hardly be achieved. For this reason, it is necessary to define acceptable degrees of variation, known as tolerances (GD\&T and ISO 1101:2017). Dimensional tolerances define the acceptable limits of mechanical elements so that they can be used. The size of these tolerances is a hundredth or even a thousandth of a millimeter. During teaching activities in the field of tolerances, it was noticed that students had a problem understanding this topic. Moreover, one of the problems encountered by students was the fact that such small values can significantly impact the functionality of an assembly that accomplishes two tolerated machine elements.

For that reason, this paper presents an automatic device for remote measuring of geometrical tolerances; in this case circularity (roundness). This device enables control, live monitoring, and reading the measured results (Bajci et al., 2016). The main aim of device development is to bring the theoretical knowledge in this field closer to students through practical exercises, even during conditions brought on by the COVID-19 pandemic.

The previously mentioned device is only one part of the remote laboratory of the Faculty of Technical Sciences in Novi Sad, which was created in such a way that performing simple exercises makes it easier for students to understand some mechanical concepts. In this way, allowing students to visualize the exercise makes the mechanical process more attractive and accurate compared to manual handling. 


\section{Basics of Circularity}

In the area of geometrical tolerances, circularity is a very common value to be measured. When a poorly machined cylindrical part rotates in the assembly, it can cause strong vibrations and noise, or even lead to assembly failure.

A cylindrical part (workpiece) is rounded if all points of the cross section are equidistant from the common center. As mentioned earlier, it is difficult to achieve a perfect circular shape. Therefore, it is necessary to determine the circularity tolerance zone. A circularity tolerance zone is defined by two concentric circles that are radial distance $\Delta T$ apart and that encloses the circular profile (ISO 1101:2017). If the diameter of the outer circle is designated as USL (upper specification limit) and the LSL (lower specification limit) of the diameter in the inner circle, then the circularity tolerance zone, shown in Figure 1, can be defined as

$$
\Delta T=(U S L-L S L) / 2
$$

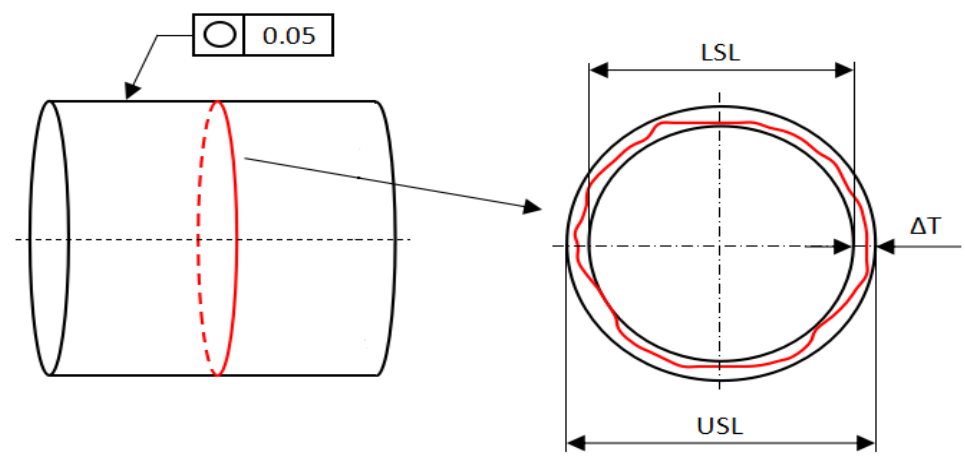

Figure 1. Representation of circularity.

All points on the surface must lie within the limits of the tolerance zone (Chiabert et al., 2018).

For determining the circularity errors several mathematical methods can be used, such as (Sui and Zhang, 2012) Minimum Zone Circles (MZC), Least Squares Circles (LSC), Maximum Inscribed Circle (MIC), and Minimum Circumscribed Circle (MCC).

\section{DESIGN AND IMPLEMENTATION}

The automatic device for remote measuring of circularity is composed of several basic parts, which can be classified as hardware units: control unit, mechanical construction, sensors, actuators, web camera, server PC; and software units: Internet access, control software and user interface. The basic parts of the device are shown in Figure 2. 


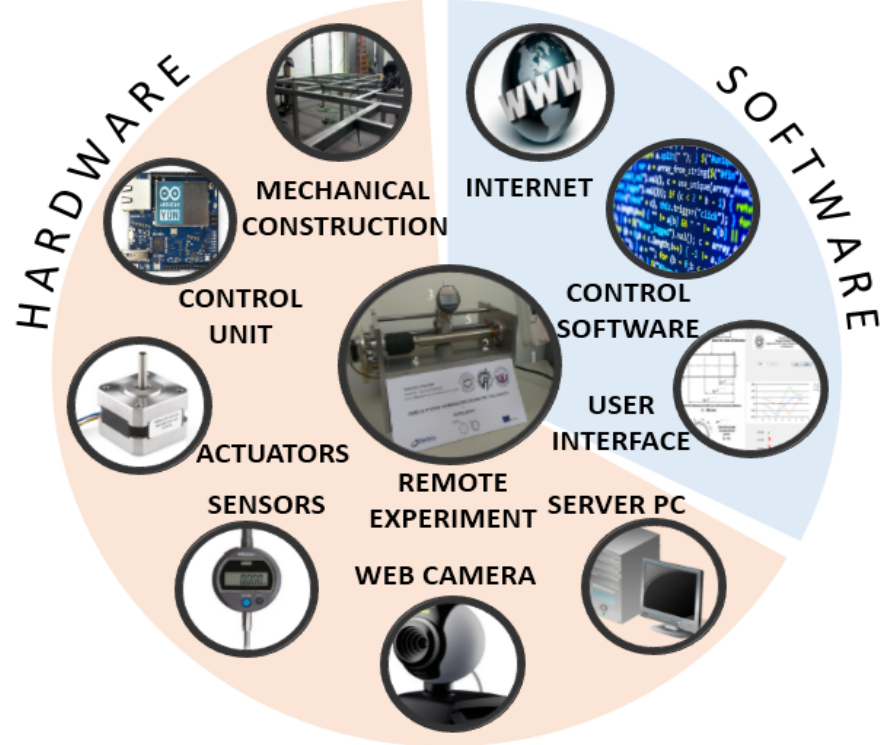

Figure 2. Basic parts of the automatic device for remote measuring of circularity.

\section{Hardware}

The developed experimental device is shown in Figure 3.

The whole measuring process can be tracked via a web camera (1). To measure throughout the whole circumference, it is necessary to rotate the workpiece (2) around its axis. For this purpose, a Mercury stepper motor (6) is used, while a digital indicator (3) is used for measurement. The digital indicator measures the relative difference from a user predefined zero point and can be moved linearly along the workpiece to measure the circularity in different positions. This movement is done by a DC motor connected to the threaded spindle (5) over two coupled gear wheels. Correct positioning of the digital indicator, along the length of the workpiece, is achieved by feedback information from the motor's incremental encoder.

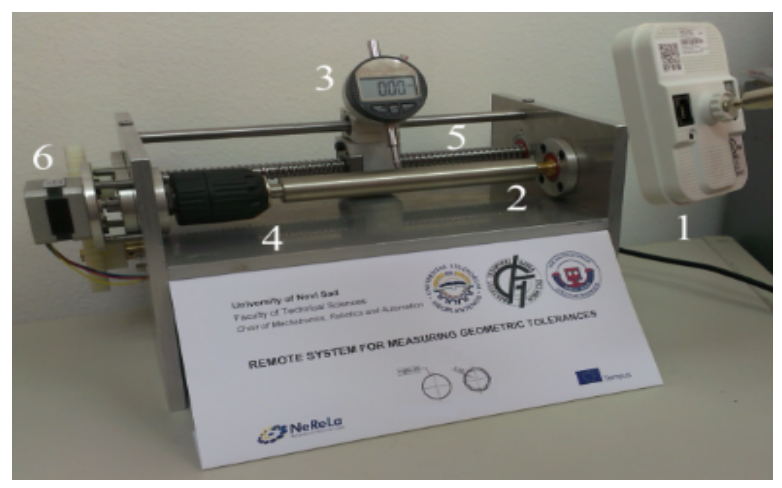
(1) Web camera
(2) Workpiece
(3) Digital indicator
(5) Mechanical construction
(6) Threaded spindle

Figure 3. The experimental device. 
The control unit of the experimental device consists of a microcontroller, a power supply, and an electronic circuit board. The Arduino YUN board is used for controlling the device remotely. It controls the DC and the stepper motors, collects the data from the indicator, and communicates with a PC. For the purpose of signal raising, a special electronic circuit is created, as shown in Figure 4. Standard electronic circuit, for reading signals from a two-channel rotary encoder, is shown in Figure 5. In Figure 6, the L6203 circuit motor driver is presented. It is used for controlling the DC motor while the L298 motor driver circuit, shown in Figure 7, is used for controlling the stepper motor.

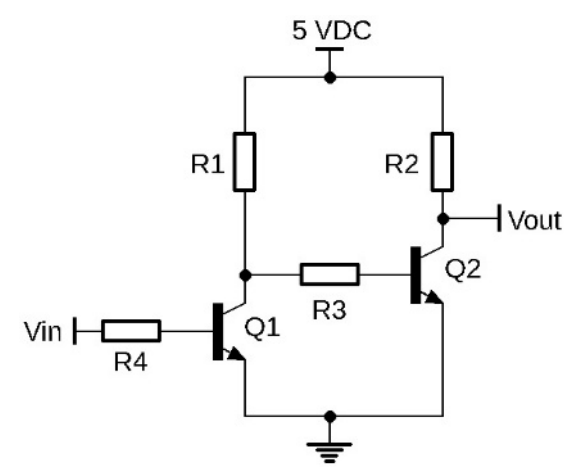

Figure 4. Electronic circuit for raising the digital indicator signal voltage level.

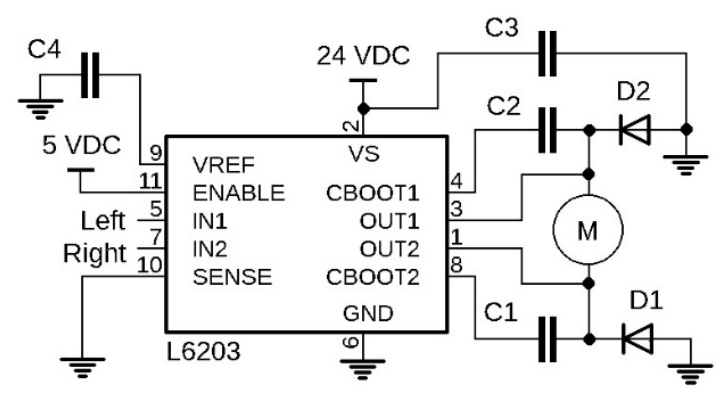

Figure 6. DC motor driver.

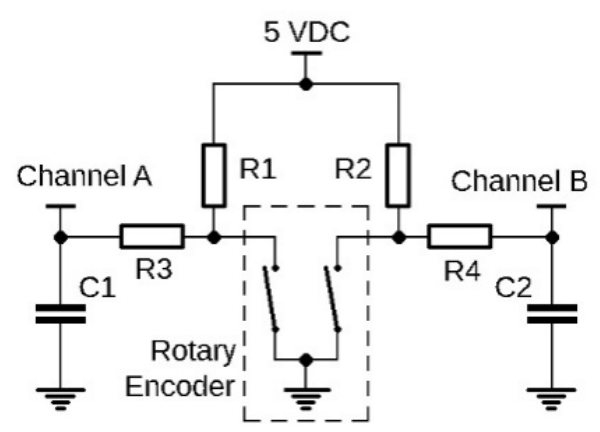

Figure 5. Electronic circuit for reading signal from the rotary encoder.

\section{User Interface}

The developed user interface is shown in Figure 8. It is very simple and friendly to use in accordance with the task for which it is intended.

On the left side of the application is a schematic representation of the workpiece. There are five fields for entering specific parameters. To launch the experiment correctly, the user must enter the following parameters that will affect the experiment: tolerance value (the value that is compared to experimentally measured values), measurement positions (user can perform the measurement in three different positions in one measurement cycle), 
and number of measuring points (this is the number of points in which the measurement is performed). The measuring workpiece is limited to a maximum of 15 points in order to shorten the measurement process.

There are several control elements on the right side of the application. The user interface communicates with the device through a serial communication. Therefore, after entering the measurement parameters, it is necessary to select the appropriate COM port, using the drop-down menu, and opening it for communication, using the Open port button. The measurement begins by pressing the Start button. At the end of the measurement, pressing the Results button will display the results in the graphical and numerical forms. Furthermore, the absolute value of the difference between the maximum and the minimum measured value, $\Delta \mathrm{T}$, is displayed for each position. If this value is less than or equal to the tolerance value, the workpiece fulfills the circularity criterion it the measuring position.

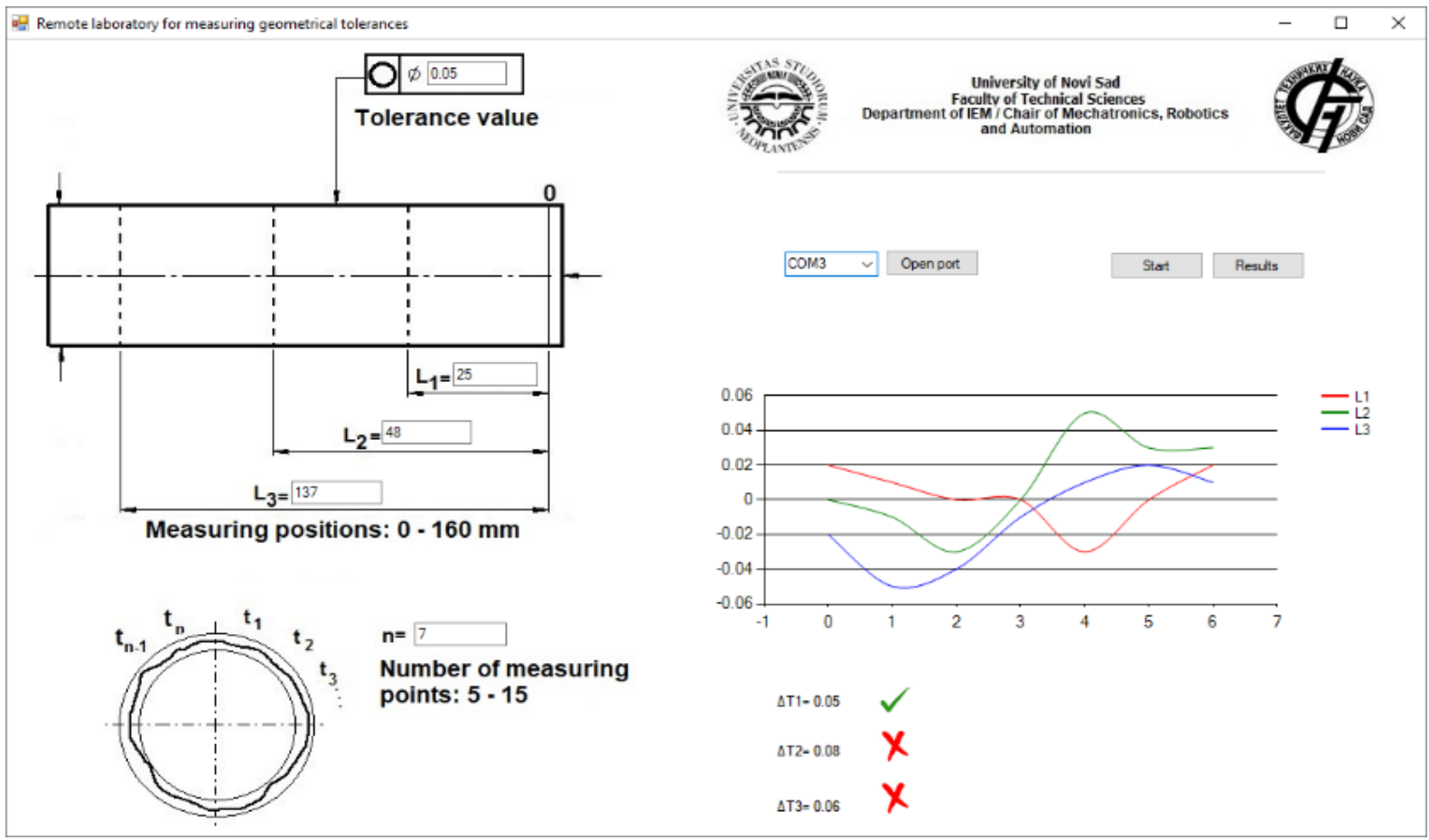

Figure 8. User interface.

\section{Remote Access}

Remote access to the experiment is provided in order to perform the experiment from a distant location. For this purpose, the CEyeClon platform was used. CEyeClon is described as a remote learning system with high security performance (CEyeClon, Education, 2016). The user connects to a remote computer, located in the laboratory, through their own computer and with a stable Internet connection. The CEyeClon platform has the ability to reserve the time for one user, and it can be easily connected to hardware components.

The configuration of the CEyeClon platform in a remote laboratory is shown in Figure 9. 


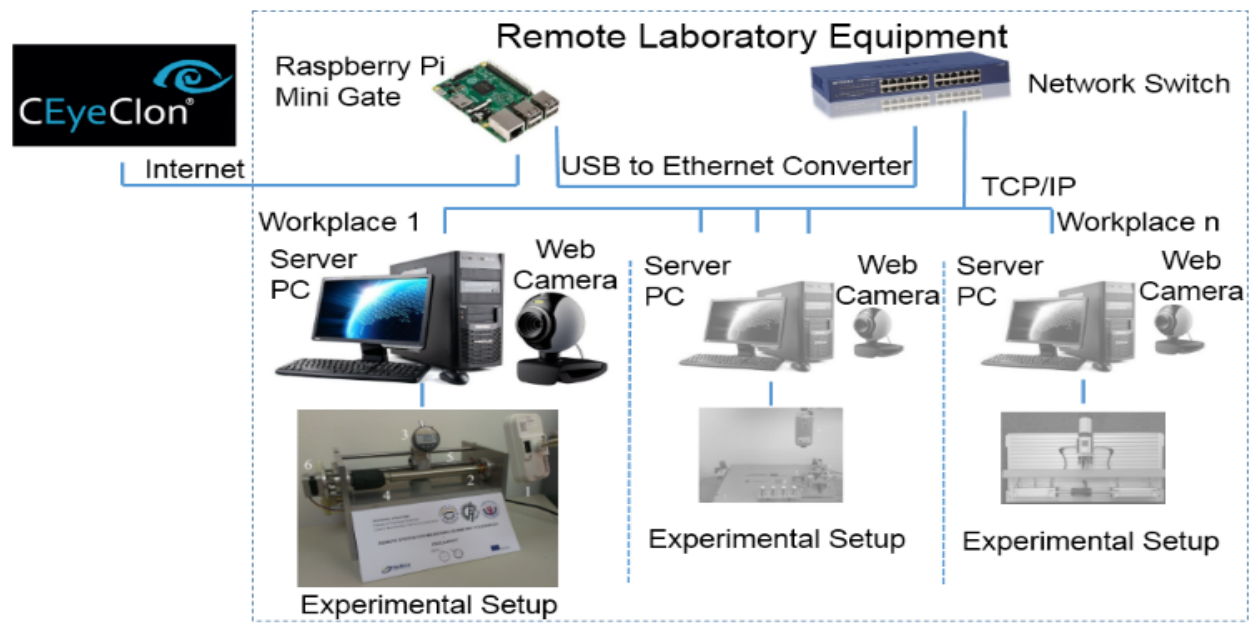

Figure 9. Remote access to the automatic device for remote measuring of circularity.

A Raspberry Pi, with a specialized code placed on a MicroSD card, represents a mini gateway to the system and is connected to the network. In general, multiple remote experiments, or workplaces, could be connected to the platform. Workplaces, which consist of a server PC, a web camera, and the physical experimental setup are connected through a network switch. If a user wanted to perform the remote experiment, it would first be necessary to contact the system administrators to get a valid username and password. The data provides the user the ability to reserve the experiment during a certain period. After logging into the system with the CEyeClon Viewer software, the user could see all the workplaces connected to the network switch, but could access only the requested one. It should be noted that the CEyeClon Viewer, due to the transition to web-based access, is no longer supported by Microsoft Windows.

The flowchart of performing the experiment is divided into four parts, as shown in Figure 10.
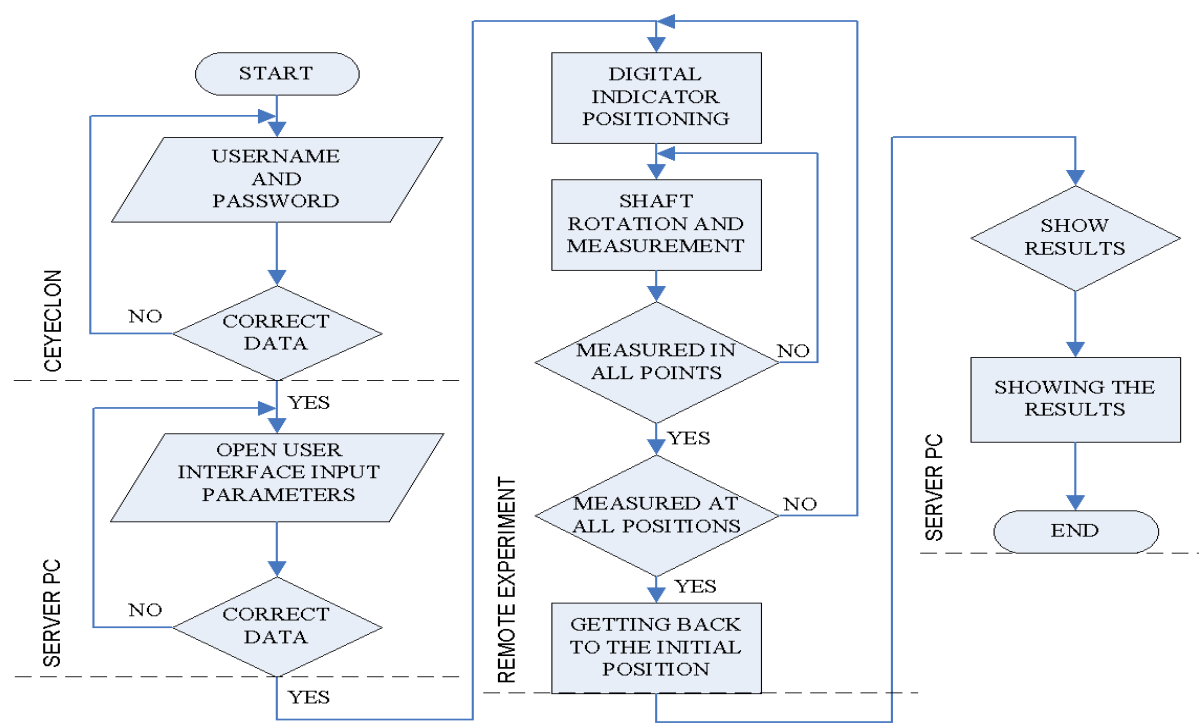

Figure 10. Flowchart of the performing the experiment. 


\section{EVALUATION}

The current version of the automatic device for remote measuring of circularity, as part of the remote laboratory, was applied to the lectures of Computer Aided Product Design and Analysis, a subject of undergraduate studies of Industrial Engineering (IE) and Information Systems Engineering (ISE) at the Faculty of Technical Sciences. After a theoretical explanation of the geometric tolerances and introduction of the device, students were left to perform the experiment independently. In the next step, they calculated the circularity errors using one of the four defined mathematical methods based on the measurement results. A total of 56 students, 38 from IE and 18 from ISE, completed the questionnaire. The results of their feedback are given in Table 1. Answers correspond to numbers 5 to 1 , where 5 is completely agree, 4 - mostly agree, 3 - partly agree, 2 - mostly disagree, and 1 - completely disagree.

Table 1. Results of the students' evaluations.

\begin{tabular}{|c|c|c|}
\hline \multirow{2}{*}{ Questions } & \multicolumn{2}{|c|}{ Average grade } \\
\hline & IE & ISE \\
\hline $\begin{array}{l}\text { (1.) Conducting this remote experiment helped me to achieve learning module's } \\
\text { objectives. }\end{array}$ & 4.73 & 4.12 \\
\hline $\begin{array}{l}\text { (2.) Conducting this remote experiment helped me to achieve learning module's } \\
\text { outcomes. }\end{array}$ & 4.50 & 3.75 \\
\hline $\begin{array}{l}\text { (3.) The remote experiment facilitated better understanding of module's } \\
\text { theoretical background. }\end{array}$ & 4.57 & 4.12 \\
\hline (4.) The remote experiment helped me to learn to use lab equipment. & 4.78 & 4.50 \\
\hline $\begin{array}{l}\text { (5.) Remote experiment within this learning module is prepared on appropriate } \\
\text { technical level. }\end{array}$ & 4.44 & 4.75 \\
\hline (6.) Experiment is easy to understand and use. & 4.47 & 4.75 \\
\hline (7.) Written manual for remote experiments clearly understandable and helpful. & 4.65 & 4.72 \\
\hline $\begin{array}{l}\text { (8.) Remote experiment was supported by adequate explanation from teacher } \\
\text { before starting. }\end{array}$ & 4.65 & 5.00 \\
\hline $\begin{array}{l}\text { (9.) User interface for remote experiment within this learning module is easy to } \\
\text { use. }\end{array}$ & 4.73 & 4.70 \\
\hline (10.) Response time after user action within running experiment is satisfying. & 4.65 & 4.50 \\
\hline (11.) Capture of experimental results is enabled. & 4.71 & 4.62 \\
\hline (12.) Storage of experimental results is enabled. & 4.65 & 4.67 \\
\hline (13.) Quality of visual display is satisfactory. & 4.62 & 4.50 \\
\hline (14.) There was no problem or stalling while working with remote experiment. & 4.25 & 4.65 \\
\hline (15.) I would like to use remote lab in other lessons of this subject too. & 4.57 & 4.63 \\
\hline \multicolumn{3}{|l|}{ (16.) Please, state the advantages of remote experiment: } \\
\hline \multicolumn{3}{|l|}{ (17.) Please, state the disadvantages of remote experiment: } \\
\hline (18.) Additional comments: & & \\
\hline
\end{tabular}


The questionnaire consisted of fifteen questions related to the design of the experiment and the user interface, as well as the relevance of the experiment to theoretical background of circularity. As can be noticed from the evaluations, the remote experiment left a positive impression on the students. The remote experiment has a total average score of 4.59 (IE) and 4.54 (ISE), which is more than encouraging for further research due to the fact that it was evaluated at two completely different study programs. The three best-rated questions at IE, Q1, Q4 and Q9, show that friendly and easy-to-use interface and laboratory equipment successfully helped students to gain new knowledge. The lowestrated question, Q14, may be the result of poor Internet connection. On the other side, at ISE, the best-rated questions are Q5, Q6 and Q8, while the lowest-rated question is Q2. The differences between the best and lowest-rated questions in two study programs can be related to the fact that students from IE are more industrially and technically oriented while ISE students are more programming and information processing oriented.

At the end of the questionnaire, students had the opportunity to give their own comments. The most prominent advantages were: "It is easier to explain theory and understand it; It is not necessary to be at the same place with the experiment; Easy access; User-friendly interface." They also stated several shortcomings, such as: "There is no audio output from the experiment; Camera delay; A good Internet connection is needed to improve video quality; Possibility of measuring only one workpiece." Some students added additional comments: "Nice innovation; Congratulations."

\section{CONCLUSION}

The remote experiment for measuring geometric tolerance, circularity, was created for the educational purpose of helping users better understand the real concepts they are studying in class. It allows the user to monitor and collect data and then compare theoretical and practical knowledge gained through real practical experimentation. Using the CEyeClon platform, the experiment was accessible from all over the world, at any time, through a web browser. It was only necessary to book a date when the experiment was available.

During the COVID-19 pandemic, and even earlier, this experiment was implemented and integrated for remote use with our faculty Learning Management System (LMS).

The remote device described in this paper was used and evaluated by 56 students of undergraduate studies of Industrial Engineering and Information Systems Engineering. The positive feedback and the relatively high average score of 4.59 and 4.54 out of 5 are impressive and encouraging for the future development of existing, and new, remote laboratories and experiments. Students also had the opportunity to leave their opinion in the form of the advantages and disadvantages of a remote device that are crucial Based on the students' comments, further work will include the replacement of the materials and mechanical concepts to ensure upgrading users' knowledge through online evaluation. Also, the next step is to modify the method of remote access to the device because the CEyeClon Viewer for Windows is no longer supported. The platform has been moved to web-based access. Another step would be offering additional support for students when performing remote experiments through the creation of a section for frequently asked questions, which can help students solve some difficulties, including access to the device and the teaching process. 


\section{REFERENCES}

Alkhaldi, T., Pranata, I. \& Athauda, R.I. 2016. A review of contemporary virtual and remote laboratory implementations: observations and findings. Journal of Computers in Education. 3:329-351. https://doi.org/10.1007/s40692-016-0068-z

Axaopoulos, P.J., Moutsopoulos, K.N. \& Theodoridis, M.P. 2012. Engineering education using a remote laboratory through the Internet. European Journal of Engineering Education. 37(1):39-48. https://doi.org/10.1080/03043797.2011.644764

Bajči, B., Dudić, S., Šulc, J., Milenković, I., Šešlija, D. \& Reljić, V. 2016. Remote system for measuring geometric tolerances: Roundness. Proceedings of the $13^{\text {th }}$ International Conference on Remote Engineering and Virtual Instrumentation. Madrid, Spain, 2016, pp. 285-286. https://doi.org/10.1109/REV.2016.7444484

Caminero, A. C., Hernández, S. Ros, R., Robles-Gómez, A., Tobarra, L. \& Granjo, P. J. T. 2016. VirTUal remoTe labORatories Management System (TUTORES): Using Cloud Computing to Acquire University Practical Skills. IEEE Transactions on Learning Technologies. 9(2):133-145, doi: 10.1109/TLT.2015.2470683

CEyeClon, Education, 2016. Available at: http://ceyeclon.com/en/ presentation/education. Accessed $13^{\text {th }}$ Apr 2017.

Chiabert, P., Maddis, M. D., Genta, G., Ruffa, S. \& Yusupov, J. 2018. Evaluation of roundness tolerance zone using measurements performed on manufactured parts: A probabilistic approach. Precision Engineering. 52:434-439. https://doi.org/10.1016/j.precisioneng.2018.02.001

Dos Santos Lopes, M.S., Gomes, I.P., Trindade, R.M., Da Silva, A.F. \& Lima, A.C.D.C. 2017. Web environment for programming and control of a mobile robot in a remote laboratory. IEEE Transactions on Learning Technologies 10(4):526-531. https://doi.org/10.1109/TLT.2016.2627565

Faulconer, E.K., Griffith, J., Wood, B., Acharyya, S. \& Roberts, D. 2018. A Comparison of Online, Video Synchronous, and Traditional Learning Modes for an Introductory Undergraduate Physics Course. Journal of Science Education and Technology. 27:404-411. https://doi.org/10.1007/s10956-018-9732-6

GD\&T (Geometric Dimensioning and Tolerancing). Symbols. Available at: https://www.gdandtbasics.com/gdtsymbols/. Accessed $20^{\text {th }}$ Feb 2020.

Geaney, G. \& O'Mahony, T. 2016. Design and evaluation of a remote PLC laboratory. The International Journal of Electrical Engineering \& Education. 53(3):212-223. https://doi.org/10.1177\%2F0020720915622468

Irmak, E., Bayindir, R. Colakand, I. \& Soysal, M. 2011. A remote laboratory experiment for 4-quadrant control of a DC motor. Computer Applications in Engineering Education. 19(4):747-758. https://doi.org/10.1002/cae.20361

ISO 1101:2017(en). 2017. Geometrical product specifications (GPS) - Geometrical tolerancing — Tolerances of form, orientation, location and run-out. Available at: https://www.iso.org/obp/ui/\#iso:std:iso:1101:ed4:v1:en. Accessed16 ${ }^{\text {th }}$ Sep 2018.

Kaluz, M., Garcia-Zubia, J., Fikar, M. \& Čirka, L. 2015. A flexible and configurable architecture for automatic control remote laboratories. IEEE Transactions on Learning Technologies 8(3): 299-310. https://doi.org/10.1109/TLT.2015.2389251

Krneta, R., Damnjanovic, Dj., Milosevic, M., Milosevic, D. \& Topalovic, M. 2012. Blended learning of DSP trough the integration of on-site and remote experiments. Technology, Education, Management, Informatics Journal 1(3): 151-160.

Lowe, D., Dang, B., Daniel, K., Murray, S. \& Lindsay, E. 2015. On the viability of supporting institutional sharing of remote laboratory facilities. European Journal of Engineering Education. 40(6):611-622. https://doi.org/10.1080/03043797.2014.1001815 
Luthon, F. \& Larroque, B. 2015. LaboREM-A remote laboratory for game-like training in electronics. IEEE Transactions on learning technologies 8(3):311-321. https://doi.org/10.1109/TLT.2014.2386337

Ožvoldova, M., Špilakova, P. \& Tkač, L. 2014. Archimedes' principle-internet accessible remote experiment. International Journal of Online Engineering (iJOE). 10(5):36-42. http://dx.doi.org/10.3991/ijoe.v10i5.3831

Reljić, V., Milenković, I., Bajči, B, Šešlija, D. \& Šulc, J. 2018. Remotely controlled compressed air spring—Design and implementation for distance education. Computer Applications in Engineering Education. 26(6):2131-2140. https://doi.org/10.1002/cae.22015

Rojko, A., Hercog, D. \& Jezernik, K. 2011. E-training in mechatronics using innovative remote laboratory. Mathematics and Computers in Simulation. 82(3):508-516. https://doi.org/10.1016/j.matcom.2010.10.017

Sit, S.M. \& Brudzinski, M.R. 2017. Creation and Assessment of an Active e-Learning Introductory Geology Course. Journal of Science Education and Technology. 26:629-645. https://doi.org/10.1007/s10956-017-97033

Sui, W. \& Zhang, D. 2012. Four Methods for Roundness Evaluation. Physics Procedia. 24(C):2159-2164. https://doi.org/10.1016/j.phpro.2012.02.317

Tekin, A., Fikret, A. \& Muammer, G. 2012. Remote control laboratory for DSP-controlled induction motor drives. Computer Applications in Engineering Education. 20(4):702-712. https://doi.org/10.1002/cae.20440

Yayla, A. \& Akar, A. 2008. Web based real time remote laboratory with LabVIEW access for analog and digital communication courses. Journal of Electrical \& Electronics Engineering 8(2): 671-681. 